\title{
As primeiras fábricas de compotas de pêssego na área rural de Pelotas: ensinando e aprendendo nos anos iniciais
}

\author{
Las primeras fábricas de compotas de melocotón en el área rural de \\ Pelotas: ensinando y aprendiendo en los años iniciales
}

\author{
The first factory of peach compotes in the rural area of Pelotas: teaching \\ and learning in the initial years
}

Lígia Cardoso Carlos ${ }^{1}$

Claudia Barbosa Pereira Souza ${ }^{2}$

Valdizan de Jesus Souza ${ }^{3}$

\begin{abstract}
Resumo
O texto apresenta e discute um projeto de ensino para os anos iniciais elaborado na disciplina Ensino, Aprendizagem, Conhecimento e Escolarização $V$ do Curso de Pedagogia da UFPel. O objetivo é despertar nas crianças o interesse por conhecer aspectos da História e da Geografia do município de Pelotas, bem como desenvolver a capacidade de investigação histórica (COOPER, 2006). Foi desenvolvido por meio de estudos sobre a produção de compotas de pêssego na área rural de Pelotas de 1950 a 1970 (BACH, 2010; BACH e VIEIRA, 2014), ou seja, sobre o que as primeiras fábricas de compotas de pêssegos representaram para as famílias, os ganhos econômicos que trouxeram para a cidade, onde estavam localizadas, como funcionavam e os benefícios e malefícios ao meio ambiente. Posteriormente, a partir dos estudos feitos, foi pensado em como o assunto poderia ser trabalhado com as crianças dos anos iniciais. Entendemos que no processo são potencializados conhecimentos na área da História, verificando as mudanças e permanências através do tempo; da Geografia, questionando o impacto na organização do espaço rural e no meio ambiente; e da Cultura, proporcionando aos alunos reflexões sobre as mudanças de vocabulário, vestimentas e formas de lazer dos sujeitos envolvidos. O projeto de ensino permitiu discutir diversas possibilidades pedagógicas para a área das ciências humanas nos anos iniciais, ampliando nossa compreensão sobre esta fase da escolarização, sobre questões que não constam nos livros didáticos e sobre a importância da formação inicial de professores.
\end{abstract}

Palavras-Chave: Anos Iniciais; Ensino de Geografia; Ensino de História; Formação de Professores

\section{Resumen}

El texto presenta y discute un proyecto de enseñanza para los años iniciales elaborado en la disciplina Enseñanza, Aprendizaje, Conocimiento y Escolarización V del Curso de Pedagogía de la UFPel. El objetivo es despertar en los niños el interés por conocer aspectos de la Historia y de la Geografía del municipio de Pelotas, así como desarrollar la capacidad de investigación histórica (COOPER, 2006). Se desarrolló por medio de estudios sobre la producción de compotas de melocotón en el área rural de Pelotas de 1950 a 1970 (BACH, 2010, BACH y VIEIRA, 2014), o sea, sobre lo que las primeras fábricas de compotas de melocotones representaron para las las familias, las ganancias económicas que trajeron a la ciudad, donde estaban localizadas, cómo funcionaban y los beneficios y maleficios al medio ambiente. Posteriormente, a partir de los estudios hechos, fue pensado en cómo el asunto podría ser trabajado con los niños de los años iniciales. Entendemos que en el proceso se potencian conocimientos en el área de Historia, verificando los cambios y permanencias a través del tiempo; de la Geografía, cuestionando el impacto en la organización del espacio rural y en el medio

\footnotetext{
${ }^{1}$ Doutora em Educação (UNISINOS); li.gi.c@ hotmail.com

${ }^{2}$ Graduanda em Pedagogia na Universidade Federal de Pelotas; claudiabsousa@ hotmail.com

${ }^{3}$ Graduando em Pedagogia na Universidade Federal de Pelotas; valdizansousa@ gmail.com
} 
ambiente; y de la Cultura, proporcionando a los alumnos reflexiones sobre los cambios de vocabulario, vestimentas y formas de ocio de los sujetos involucrados. El proyecto de enseñanza permitió discutir diversas posibilidades pedagógicas para el área de las ciencias humanas en los años iniciales, ampliando nuestra comprensión sobre esta fase de la escolarización, sobre cuestiones que no constan en los libros didácticos y sobre la importancia de la formación inicial de profesores.

Palabras Clave: Años iniciales; Enseñanza de Geografía; Enseñanza de Historia; Formación de profesores

\begin{abstract}
The text presente and discusses a teaching project for the initial years elaborated in the discipline Theaching, Learning, Knowledge and Schooling V for the UFPel Pedagogy Course. The objective is to awaken in the children the interest to know aspects of History and Geography of the municipality of Pelotas, as well as to develop the capacity of historical research (COOPER, 2006). The work was developed through studies on the production of peach compotes in the Pelotas rural area from 1950 to 1970 (BACH, 2010; BACH and VIEIRA, 2014), in other words, what the first peach compote factories represented for the families, the economic gains they brought to city, where they were located, how they worked, and the benefits and harms of the environment. Subsequently, from the studies done, the project was thought about how the topic could be worked out with children from the teaching for initial years. In the process, we understand that knowledge are enhanced in the History area, checking the changes and permanencies through time; in the Geography area, questioning the impact on the organization of the rural space and the environment; and in the Culture area, giving students reflections about the changes in vocabular, vestment, and forms of recreation of the subjects involved.The teaching project made possible to discuss several pedagogical possibilities for the area of human sciences in the initial years, expanding our understanding about this phase of schooling, about issues not included in textbooks and about the importance of initial teacher training.
\end{abstract}

Keywords: Teaching for initial years; Geography teaching; History teaching; Teacher training.

\title{
1. Introdução
}

O texto apresenta e discute um projeto de ensino desenvolvido no âmbito da disciplina Ensino, Aprendizagem, Conhecimento e Escolarização $V$ do Curso de Pedagogia da Universidade Federal de Pelotas (UFPel). A disciplina tem como objetivos principais caracterizar o ensino da História e da Geografia nos anos iniciais, examinar seus pressupostos teóricos e princípios metodológicos e discutir as possibilidades dessas áreas do conhecimento como campo de estudos para a compreensão do meio social, da cultura, do espaço e do tempo no início do processo de escolarização. Neste contexto, foi indicado aos alunos matriculados organizarem uma proposta pedagógica para os anos iniciais da escolarização. Diante do desafio, muitas propostas foram planejadas e uma delas trataremos aqui. Selecionamos como conteúdo disciplinar a produção de compotas de pêssego na área rural de Pelotas de 1950 a 1970 (BACH, 2010; BACH e VIEIRA, 2014). A ideia foi desenvolver, por meio do estudo daquele ambiente, atividades que possibilitem aos alunos conhecerem aspectos do passado, suas complexidades e inter-relações, bem como ser fonte de inspiração para questionar e compreender o presente. 
Trata-se de uma proposta com os objetivos de despertar nas crianças o interesse pela História e pela Geografia do município de Pelotas, possibilitar a compreensão de processos de mudança e permanência no espaço e no tempo e desenvolver a capacidade de investigação histórica que, segundo Cooper (2006, p. 175), “envolve a compreensão de conceitos do tempo: a mensuração do tempo, continuidade e mudança, as causas e efeitos de eventos e de mudanças ao longo do tempo, semelhanças e diferenças entre períodos". Cabe ressaltar que a mesma não foi realizada com alunos da educação básica, a intenção, durante a formação inicial no Curso de Pedagogia, era fazer um exercício teórico-prático que indicasse possibilidades de ensino e aprendizagem das ciências humanas nos anos iniciais. Foram privilegiadas estratégias por meio de conversas, pesquisas, comparações de fatos, leituras de imagens e interpretações com o intuito de desenvolver o senso crítico e a responsabilidade de ser e estar no mundo.

Além disso, a proposta pedagógica aqui apresentada leva em consideração proporcionar um aprendizado que permita aos alunos compreenderem que, além da história ensinada nos livros didáticos, existe uma outra história que está presente na oralidade, na memória, na música, nos hábitos, nas lutas cotidianas, etc. A ideia é desenvolver atividades que envolvam os alunos em práticas de estudo e de indagações, possibilitando que entendam que a história é um processo dinâmico e que há uma diferença entre os fatos contados e os fatos vividos.

As aprendizagens sobre as ciências humanas nos anos iniciais podem ser empreendidas a partir das vivências dos familiares e dos sujeitos da comunidade. Por meio delas é factível identificar que essas vivências se transformam e são transformadas no tempo, no espaço e nas relações sociais. Possibilitar que as crianças conheçam o seu entorno por meio das fontes orais, através de conversas com familiares e vizinhos, permite que elas construam sua identidade, considerando sua história cultural. Portanto, as atividades escolares devem ser pensadas de forma que "a vivência com as crianças seja encantadora", mesmo que “desafiadora e as vezes tensa e ambígua”. (GONZÁLEZ, 2012, p. 17)

A construção da identidade também leva em conta a construção das noções de diferença e semelhança, permitindo que a criança compreenda a distinção entre o eu e o outro. Esse tipo de conhecimento é de fundamental importância na formação moral da criança, pois proporciona que respeitem os limites dos colegas e os seus próprios e compreendam diferenças de gênero, etnia, religião, classe e geração.

\section{Construindo possibilidades de aprendizagem}


Para desenvolver o projeto de ensino iniciamos pesquisando sobre as primeiras fábricas de compotas de pêssego no município de Pelotas e o que representaram para as famílias naquele período, os ganhos econômicos que trouxeram para a cidade, onde eram localizadas, como funcionavam e a tecnologia usada na sua produção. Também, como o pêssego era cultivado e tratado, os benefícios e malefícios ao meio ambiente, as pessoas responsáveis pelas fábricas, quem eram os funcionários, as condições de trabalho e os vínculos empregatícios.

Conforme estudo de Bach (2010), ressaltamos que as décadas de 1950 a 1970 representaram o apogeu e o declínio das fábricas de compotas de pêssego na zona rural de Pelotas. Haviam trinta fábricas nos anos de 1950, cinquenta e sete na década de 60 e no ano de 1970 vinte e nove unidades em funcionamento. O declínio estava relacionado à vinda de indústrias conserveiras do centro do país para a região, com um suporte tecnológico mais avançado.

$\mathrm{O}$ autor ressalta que a área do trabalho abrange o município de Pelotas antes das emancipações dos distritos de Morro Redondo, Turuçu, Arroio do Padre e Capão do Leão. Inicialmente, a atividade de produção era bastante artesanal e restrita a unidades familiares. Porém, o formato original expande-se para as fábricas, juntamente com os pomares que encontraram no município clima e solo adequados para a produção do pêssego.

Ressaltamos a importância do docente se apropriar de forma consistente dos conteúdos a serem trabalhados em sala de aula para, em uma confluência teórico-metodológica, tomar decisões práticas. Nesse sentido, o autor nos informa que:

Os dados obtidos na pesquisa nos permitem falar de um espaço industrial que, formado na região colonial, gerou uma grande abertura de postos de emprego, quer na lavoura, cuidando do pomar, ou na safra, com as contratações de safristas nas fábricas, inclusive utilizando mão-de-obra da zona urbana para suprir as vagas que a colônia não preenchia. [...] Esse processo de trabalho, envolvendo grupos familiares, apresentava um alto grau de informalidade, pois, de acordo com os relatos orais, poucas unidades fabris tinham um registro empregatício das pessoas que ali trabalhavam e via de regra o recolhimento de tributos e contribuições era feito de maneira bastante parcial. (BACH, 2010, p.75-76)

O estudo sobre achados de pesquisa é fundamental para potencializar o espaço da sala de aula como espaço de aprendizagem, permitindo fazer comparações, identificar mudanças e permanências, bem como outras formas de convívio entre as pessoas e os grupos.

Posteriormente, pensamos em como o assunto pode ser apresentado para as crianças dos anos iniciais. Consideramos adequado construir um grupo de perguntas sobre a produção e o consumo de pêssego no período de 1950 a 1970, para que os alunos possam ter uma 
primeira aproximação com o tema entrevistando pessoas de suas comunidades ou seus familiares que viveram na época indicada.

Nas aulas seguintes, deve ser feita a sistematização das respostas trazidas pelos alunos considerando o tempo, espaço e o grupo social nelas presentes, estimulando que os alunos dos anos iniciais falem sobre suas descobertas, exponham dúvidas e inferências, induzindo-os ao raciocínio histórico. É importante que o professor faça ênfase nos marcadores temporais (séculos, mês, ano e dia), nos indicadores de duração, sucessão e simultaneidade, nas características espaciais e nos grupos sociais. Levando em conta Cooper (2006, p.175), quando afirma que "os historiadores sequenciam as fontes para traçar as causas e efeitos de mudanças ao longo do tempo".

É adequado que sejam distribuídos textos informativos e imagens sobre as primeiras fábricas de compotas de pêssego e as fábricas atuais. Como exemplo, as duas fotos abaixo:

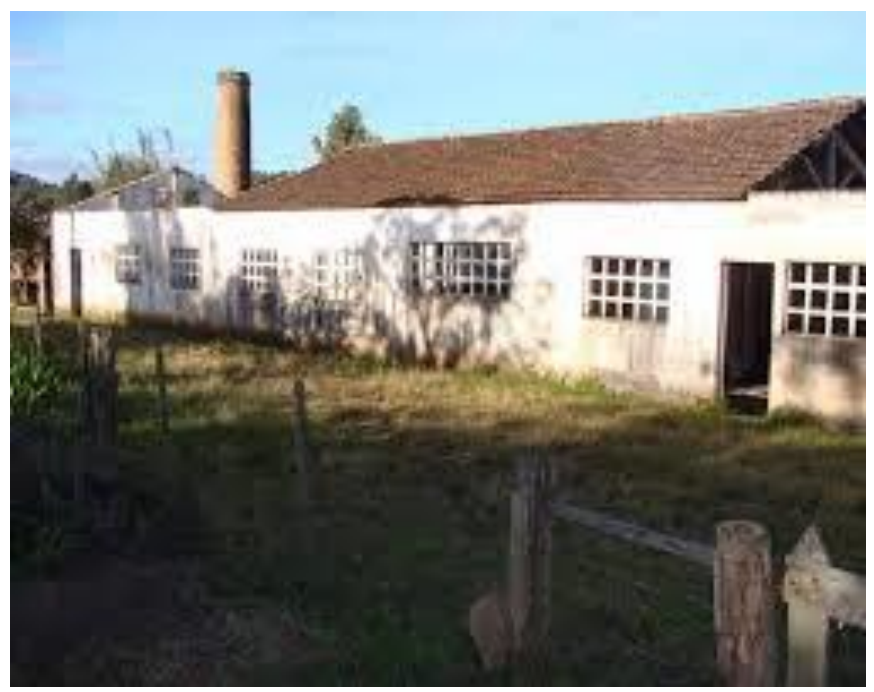

Figura 1- Estado atual da fábrica de Pedro Juvêncio Vergara na colônia Santo Antônio. Fonte: BACH, 2010, p. 77

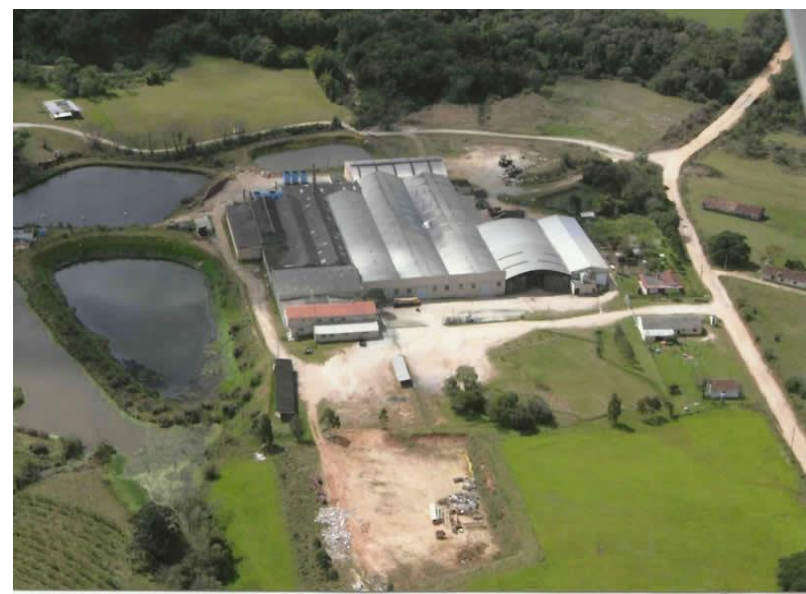

Figura 2 - Indústria de Conservas Schramm - Distrito Cascata em Pelotas-RS. Fonte: Site da Indústria de Conservas Schramm (http://www.schramm.ind.br/) 
A partir da leitura das imagens é possível identificar mudanças na arquitetura das fábricas, bem como nos materiais usados na estrutura dos prédios e a permanência da localização na zona rural. Com o auxílio de outros textos e fotografias é possível inferir as alterações na tecnologia para o manuseio e tratamento da fruta até o seu destino final.

Seguindo com a proposta de leitura de imagens, abaixo uma fotografia do interior de uma fábrica em atividade, no ano de 1971.

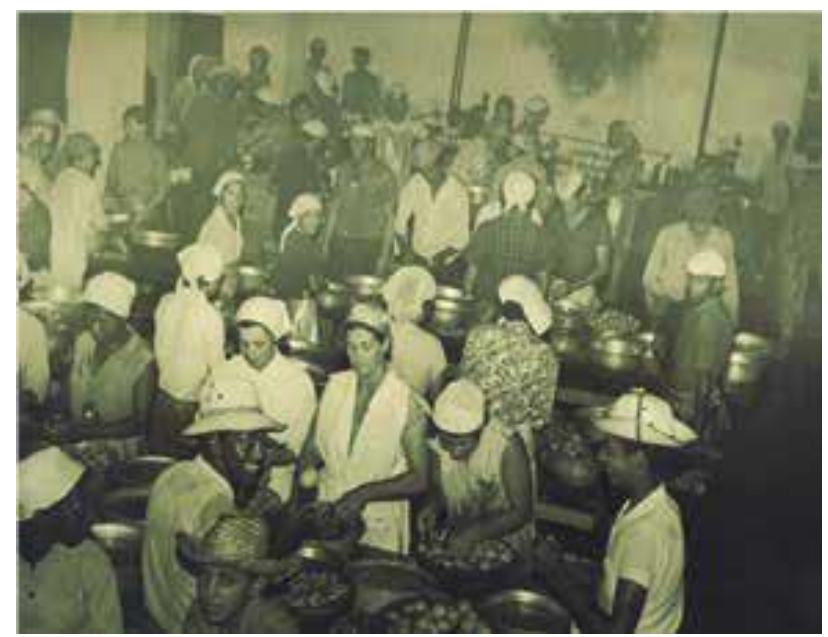

Figura 3 - Fábrica de João Casarin em atividade, Colônia Maciel, $8^{\circ}$ Distrito de Pelotas, 1971. Fonte: BACH e VIEIRA, 2014, p. 123.

A foto instiga reflexões sobre as diferentes etnias que compõem o grupo de trabalhadores, a presença de homens e mulheres na linha de produção, as condições de trabalho, o trabalho manual em contraposição ao avanço da tecnologia que demanda menos trabalhadores no interior da fábrica.

Ainda, chamou-nos atenção as duas fotos a seguir:

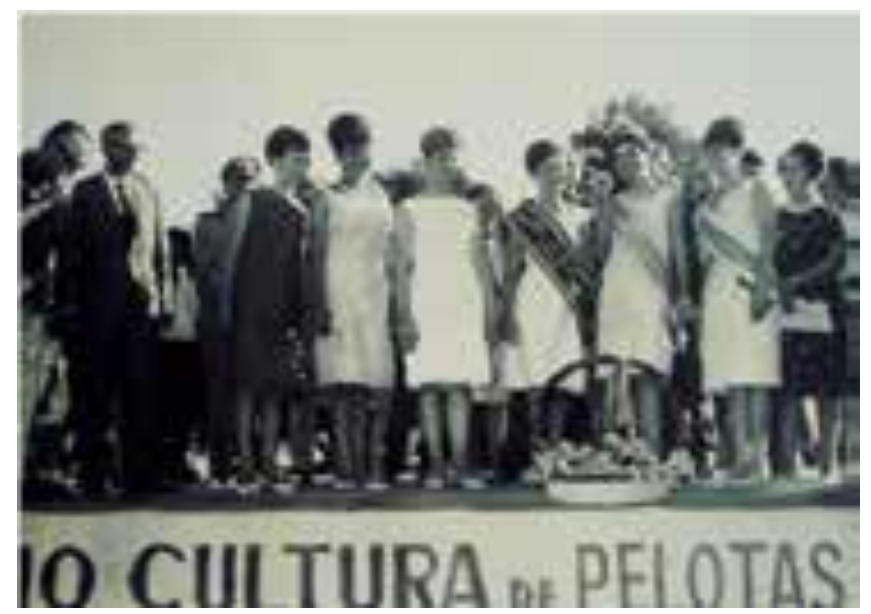

Figura 4 - Presença da Rádio Cultura de Pelotas nos eventos coloniais. Escolha da Rainha do Pêssego de 1965. Fonte: BACH e VIEIRA, 2014, p.124 


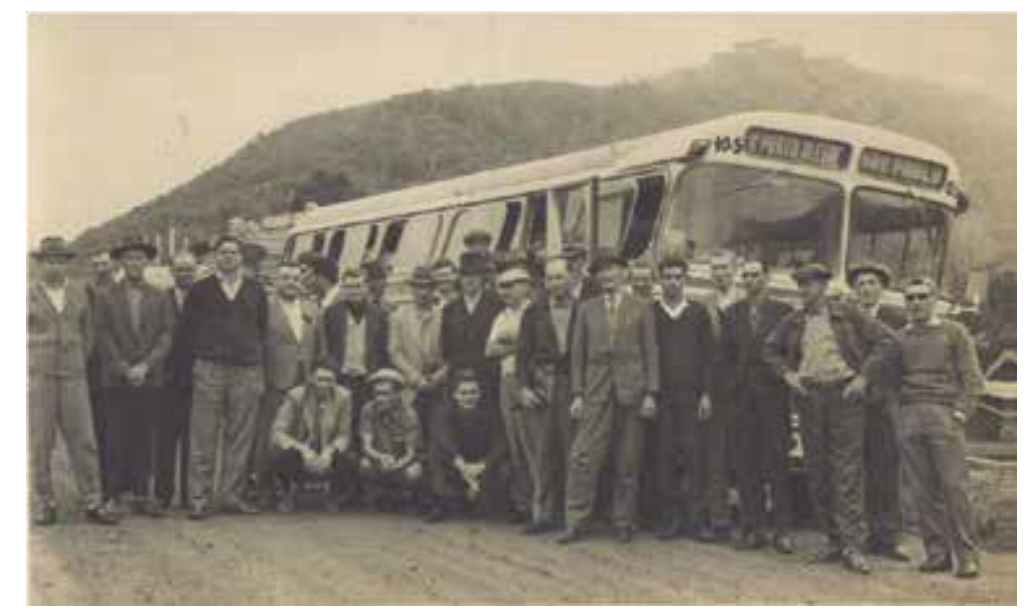

Figura 5- Viagem patrocinada pela indústria conserveira de Pelotas, aos seus colaboradores, para uma visita à indústria e pomares da Cica, em São Paulo. Meados da década de 1960.

Fonte: BACH e VIEIRA, 2014, p.124

Observando a figura 4, surgem outros temas para estudo e reflexão, os quais abrem possibilidades para a aprendizagem sobre o espaço, o tempo e as relações sociais. As dinâmicas culturais em torno das fábricas incluem os concursos de beleza, tão em voga na época, e, também, abarcam jogos de futebol, times e torcidas organizadas, festas e bailes.

A figura 5 explicita a existência de indústrias conserveiras e pomares em outros estados do país e a existência de vínculos entre os produtores locais com os demais. Com os alunos é interessante observar o meio de transporte representado na fotografia e sua estética datada, bem como identificar - com o uso de mapas - o possível trajeto a ser feito naquele período histórico e as condições de tráfego. As rodovias existentes hoje são as mesmas da época? Quanto tempo levaria a viagem? Que outros meios de transporte poderiam ser usados e quais as vantagens e desvantagens?

Observando as duas figuras percebe-se a prevalência de mulheres na figura 4 e a exclusividade de homens na figura 5. Podem ser discutidos, com os estudantes, os motivos desse fenômeno. Quais os espaços destinados aos homens e mulheres na atualidade e em décadas passadas? Por que as mulheres não estão entre os passageiros da viagem para São Paulo?

Dialogando com outro texto, que também discute uma prática pedagógica nos anos iniciais na área das ciências humanas, reconhecemos que:

A observação, o registro do observado, a busca de dados através de entrevistas, a consulta de documentos e imagens, a reflexão e a comparação com outras intervenções no espaço urbano possibilitam a compreensão da dinamicidade do espaço, das mudanças ao longo do tempo, das organizações sociais no mundo do trabalho e da noção difundida de progresso, entre outras coisas. (CARLOS, 2015, p.55) 
Para que o processo fique mais significativo é possível, também, programar uma saída de campo para visitar os locais estudados. Posterior a estas atividades, é importante realizar modos de sistematização das aprendizagens que podem ser no formato de cartazes, rodas de conversa e/ou textos coletivos.

\section{Ampliando compreensões na formação e na ação pedagógica}

A partir das descobertas dos alunos, são desenvolvidos conhecimentos nas seguintes áreas:

1) História - Verificando as mudanças e permanências através dos anos e ampliando os conhecimentos sobre tempo, espaço e grupo social, levando em consideração perguntas como: quais as diferenças entre as fábricas antigas e as atuais? Como aconteceram essas mudanças? Quanto tempo se passou? O que aconteceu para que as fábricas fechassem?

2) Geografia - Compreendendo os limites territoriais dos municípios e os processos de emancipação, aspectos da economia do município nas décadas de 50, 60 e 70 do século XX, podendo estabelecer relações com elementos da economia atual do município. Podem ser realizados estudos utilizando, por exemplo, os rótulos de compotas de pêssegos no mercado atualmente para identificar a circulação das mercadorias.

3) Ecologia - Questionando qual o impacto que os descartes das fábricas causaram ao meio ambiente, principalmente aos arroios, considerando indagações como: O que foi feito para preservar o meio ambiente? Qual a importância de cuidar do meio ambiente? Os estudos podem ser ampliados tendo em conta as questões do lixo urbano, da reciclagem e da conscientização da comunidade e da família.

4) Cultura - Proporcionando aos alunos reflexões sobre as mudanças de vocabulário, as palavras que foram modificadas ou que já estão em desuso, as formas de lazer, como se divertiam e até a questão das roupas que usavam. Este tipo de proposta proporciona um aprendizado através da pesquisa, permitindo que os alunos entendam que a história é um processo dinâmico e que na investigação histórica as vezes é necessário usar um vocabulário específico, como também encontrar palavras ou costumes que já estão em desuso, ou "palavras inventadas por historiadores para descrever períodos ou movimentos” (COOPER, 2006, p.175). Ainda, é necessário a investigação para entender os diferentes pontos de vista, as lacunas entre a história contada e a história vivida, assim como levar os alunos a descobrirem e desenvolverem modos próprios de interpretar a história sobre as fábricas de compotas do pêssego, sobre as formas de lazer, a produção de cultura e outros tantos aspectos do município e da região.

Ao realizarmos o projeto de ensino tivemos a oportunidade de discutir diversas possibilidades pedagógicas para a área das ciências humanas nos anos iniciais, ampliando nossa compreensão sobre esta fase da escolarização, bem como discutir saberes que constituem a docência no ensino dos anos inicias. Especificamente, com o desenvolvimento 
de nosso projeto, conhecemos um pouco da história de Pelotas que não consta nos livros didáticos, bem como pudemos perceber o potencial do assunto para desenvolver noções de espaço, tempo e grupo social e até mesmo de estudos interdisciplinares.

\section{Referências}

BACH, A. N. O patrimônio industrial rural: as fábricas de compotas de pêssego em Pelotas 1950 a 1970. Revista Memória em Rede, vol. 02, n. 2, p.72-80, 2010. Disponível em: https://periodicos.ufpel.edu.br/ojs2/index.php/Memoria/article/view/9561. Acesso em Acesso em: 25 agosto 2018. (Artigo em Periódico Digital)

BACH, A. N.; VIEIRA, M. A. As Fábricas de compotas de pêssego na zona rural em Pelotas (1950 a 1970). In: Luís Rubira. (Org.). Almanaque do Bicentenário de Pelotas.

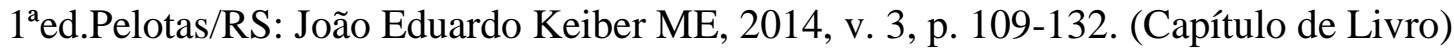

CARLOS, L. C. Os anos iniciais como espaço e tempo de ensinar e aprender as ciências humanas. In: CARLOS, L. C. (Org.) Ciência Humanas no Ensino Fundamental: reflexões, iniciativas e propostas. Pelotas: Ed. UFPel, 2015. p. 49-58. (Capítulo de Livro)

COOPER, H. Aprendendo e ensinando sobre o passado a crianças de três a oito anos. Educar, Curitiba, Especial, p. 171-190, 2006. Disponível em: https://revistas.ufpr.br/educar/article/download/5541/4055. Acesso em: 10 de agosto de 2018 . (Artigo em Periódico Digital)

GONZÁLES, F. J. Prática pedagógicas em Educação Física: Espaço, Tempo e corporeidade. Erechim: Edelbra, 2012. 144 p. (Obra Completa) 